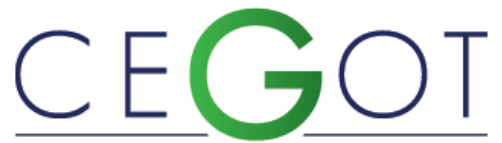

Centro de Estudos de Geografia e Ordenamento do Território
CORRÊA, LETÍCIA RAMIRES

Universidade Federal de Santa Maria - Departamento de Geociências, Centro de Ciências Naturais e Exatas

SANTA MARIA, BRASIL

leticiarcorrea@gmail.com

FollmanN, FERNANDA

Universidade de Coimbra - Departamento de Ciências da Vida da

Faculdade de Ciências e Tecnologia.

COIMBRA, PORTUGAL

fermariafoll@gmail.com

Foleto, EliANE

Universidade Federal de Santa Maria - Departamento de Geociências, Centro de Ciências Naturais e Exatas

SANTA MARIA, BRASIL

efoleto@gmail.com

Costa, FRANCISCO DA SILVA

Universidade do Minho - Centro de Estudos de Comunicação e

Sociedade.

GUIMARÃEs, PoRTUGAL

costafs@geografia.uminho.pt

VieRA, ANTÓNIO

Universidade do Minho - Centro de Estudos de Comunicação e

Sociedade.

GUIMARÃEs, PoRTUGAL

vieira@geografia.uminho.pt

\title{
O papel dos privados na gestão de áreas protegidas: $O$ caso da Fundação MO'Ã na Reserva Particular do Patrimônio Natural (RPPN) Estadual MO'Ã/BRASIL e da Irmandade da Penha no Monte da Penha/PORTUGAL.
}

The role of private individuals in the management of protected areas: The case of the MO'Ã Foundation in the State Private Reserve of Natural Heritage (RPPN) MO'Ã / BRAZIL and the Sisterhood of Penha in the Mountain of Penha / PORTUGAL.

Referência: Corrêa, Letícia Ramires; Follmann, Fernanda; Foleto, Eliane; Costa, Francisco da Silva; Viera, António (2021). O papel dos privados na gestão de áreas protegidas: O caso da Fundação MO'Ã na Reserva Particular do Patrimônio Natural (RPPN) Estadual MO'Ã/BRASIL e da Irmandade da Penha no Monte da Penha/PORTUGAL. Revista de Geografia e Ordenamento do Território (GOT), n.o 21 (Junho). Centro de Estudos de Geografia e Ordenamento do Território, p. 188-207, dx.doi.org/ 10.17127/got/2021.21.008

\section{RESUMO}

A Fundação MO'Ã do Rio Grande do Sul/Brasil é uma Organização Não-Governamental (ONG) de Estudos e Pesquisas para a Proteção e Desenvolvimento Ambiental e atua através de ações e projetos voltados para a Educação Ambiental. Em 2007 a Fundação MO'Ã recebeu por doação uma área de 24 hectares de Mata Atlântica que foi classificada em 2015 
como Reserva Particular do Patrimônio Natural (RPPN). Em Guimarães, Portugal, a Irmandade de Nossa Senhora do Carmo é proprietária de uma área de cerca de 60 hectares onde faz a receção dos devotos e promove o manejo do espaço verde e a manutenção das infraestruturas turísticas e do património religioso. Em 2019, o Município de Guimarães apresentou a candidatura da Monte da Penha a Área Protegida de âmbito local, num processo ainda em avaliação pelo Instituto da Conservação da Natureza e das Florestas. 0 trabalho apresentado visa inferir o papel da iniciativa privada na administração e gestão partilhada de áreas protegidas, numa análise comparativa entre a Fundação MO'Ã e a Irmandade da Penha. A partir de uma revisão sistemática em uma base de dados em periódicos (CAPES, EBSCO, SCIELO, Repositórios Científicos de Acesso Aberto de Portugal), relatórios, trabalho de campo e entrevistas, concluímos que as instituições privadas têm fundamental relevância tanto no ato de incentivar a criação de áreas protegidas, como de gerir em paralelo ao Estado estas áreas, promovendo o principal objetivo que é a conservação e/ou proteção da natureza de forma sustentável.

Palavras-chave: Território; Gestão; Espaços Protegidos; Turismo.

\section{ABSTRACT}

The MO'Ã Foundation in Rio Grande do Sul / Brazil is a Non-Governmental Organization (NGO) of Studies and Research for Environmental Protection and Development and works through actions and projects aimed at Environmental Education. In 2007 the MO'Ã Foundation acquired an area of 24 hectares of Atlantic Forest that was classified as a Private Reserve of Natural Heritage (RPPN), in 2015, after a long and complex process. In Guimarães, Portugal, the Sisterhood of Nossa Senhora do Carmo da owns about 60 hectares of the area where it receives the devotees and promotes the management of green space and the conservation of tourist infrastructure and religious heritage. In 2019, the Municipality of Guimarães submitted the application of Monte da Penha to a locally protected area, in a process still under evaluation by the Institute for the Conservation of Nature and Forests. The work presented aims to infer the role of the private sector in the administration and shared management of protected areas, in a comparative analysis between the MO'Ã Foundation and the Sisterhood of Penha. Based on a systematic review of a database in journals (CAPES, EBSCO, SCIELO, Open Access Scientific Repositories of Portugal), documents, fieldwork and interviews, we conclude that private institutions assume a fundamental relevance in the governance of areas protected, ensuring the main objective of these: the conservation and / or protection of nature in a sustainable way.

Keywords: Territory; Management; Protected Spaces; Tourism.

\section{Introdução}

De acordo com a International Union for Conservation of Nature (IUCN) as áreas protegidas devem definir estratégias de conservação e gestão de áreas com características naturais relevantes, que incluam atividades de investigação científica, ações de preservação da 
biodiversidade, a manutenção de serviços ambientais, recreação e educação ambiental e a manutenção da diversidade cultural (IUCN,2018).

As áreas protegidas totalizam atualmente 202.467 registradas no Banco de Dados sobre Áreas Protegidas (WDPA), cobrindo cerca de 19,2 milhões de $\mathrm{km}^{2}$ da extensão mundial. Destas, 4,5\% são áreas protegidas de domínio privado (UNEP-WCMC \& IUCN, 2016), um valor considerado de relevância na conservação e/ou proteção da biodiversidade (UNEPWCMC \& IUCN, 2016). Dentro destas, destacamos as áreas protegidas de propriedade privada que atuam como ferramenta capaz de potencializar a conservação.

Neste artigo visamos inferir o papel da iniciativa privada na administração e gestão partilhada de áreas protegidas, numa análise comparativa entre Portugal e Brasil, abordando os casos da Reserva Particular do Patrimônio Natural (RPPN) Estadual MO'Ã (RS/Brasil) e o Monte da Penha ${ }^{1}$ (Guimarães/Portugal). As áreas protegidas privadas referem-se a propriedade de indivíduos, famílias ou outras entidades não públicas como Organizações Não Governamentais (ONGs) para fins de conservação. As áreas protegidas privadas atendem às necessidades de conservação, contribuindo substancialmente para o aumento das populações de espécies e para a manutenção da conectividade ecológica (Clough, 2000). Uma terra privada que não possui características específicas em seus recursos naturais pode ser classificada como área protegida privada e compor a rede nacional (Instituto da Conservação da Natureza e das Florestas, ICNF). Assim como as RPPNs, as áreas protegidas privadas são solicitadas pelo proprietário da área, bem como um titular autorizado das ONGs ambientais ou entidades legais de direito privado.

\subsection{O caso da Reserva Particular do Patrimônio Natural (RPPN) estadual MO'Ã/BRASIL e da Monte da Penha/PORTugal.}

Neste Diante da necessidade de conservação da natureza e na busca pela preservação de atributos naturais relevantes, a Fundação MO'Ã e a Irmandade da Penha exercem um papel fundamental na gestão de áreas protegidas privadas. A RPPN estadual MO'Ã foi instituída

\footnotetext{
${ }^{1}$ A proposta de classificação da Penha como Área Protegida (Paisagem Protegida Local) encontra-se em fase de conclusão de avaliação pelo ICNF.
} 
em 2015 pela Portaria $\mathrm{n}$ 80, de 15 de junho, e tem por finalidade promover a proteção dos recursos ambientais e a conservação da diversidade biológica (Rio Grande do Sul, 2015). Desde a sua doação até à sua instituição em 2015, os Instituidores e mantenedores da Fundação MO'Ã foram os responsáveis pelo processo de criação e gestão da RPPN. Em 2007 adquiriram a propriedade no Rincão dos Minellos, em Itaara, e doaram-na à Fundação MO’Ã, por ser uma área com características naturais relevantes (Chami, Deon \& Silva, 2014). A área da RPPN (Figura 1) está localizada no município de Itaara, Estado do Rio Grande do Sul e possui cerca de 24 hectares. Dentre os condicionantes naturais que a valorizam como área protegida, está a sua integração à zona núcleo da Reserva da Biosfera da Mata Atlântica, reconhecida como um patrimônio mundial pela UNESCO. Também a flora assume um destaque, tendo em vista os 277 taxa vegetais (nativos do Brasil) identificados no levantamento florístico da RPPN (Ferrarese, 2016).

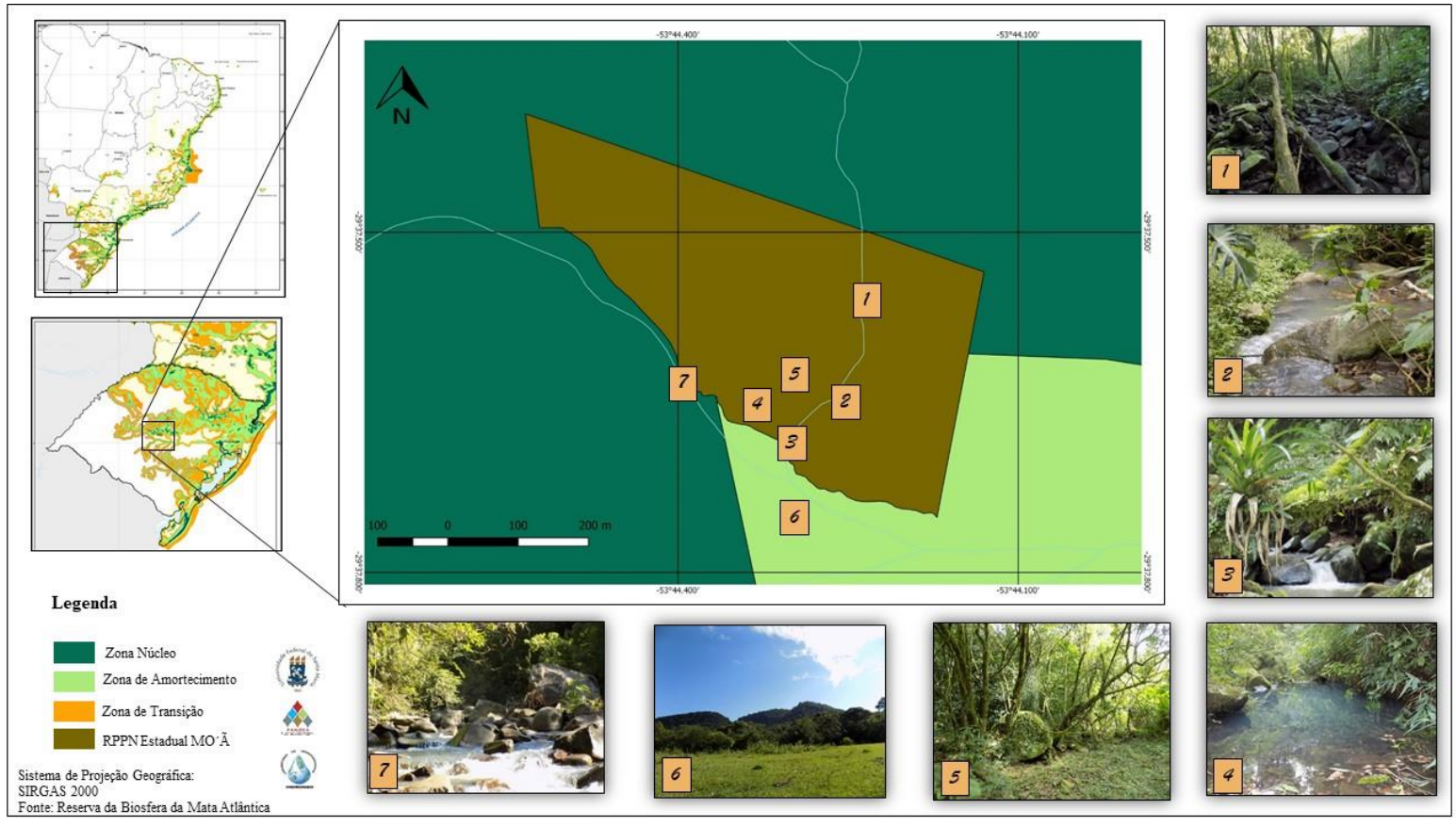

Figura 1 - Localização da RPPN Estadual MO'Ã na Reserva da Biosfera da Mata Atlântica (Brasil, RS).

Fonte: Reserva da Biosfera da Mata Atlântica, 2019. Org: Autores. 
Outro atributo é ser uma área estratégica para implementação do Corredor Ecológico da Quarta Colônia². A Secretaria Estadual do Meio Ambienta (SEMA) considerou o excelente estado de conservação da área situada na escarpa do Planalto Meridional Brasileiro e por possuir declividades acentuadas, apresentando escarpas cobertas por florestas subtropicais de grande porte (Corrêa \& Figueiró, 2017).

O atributo hídrico também é um critério importante na paisagem da RPPN Estadual MO'Ã (Corrêa \& Figueiró, 2017). A área é drenada pelos canais que compõem a bacia Arroio Manuel Alves, afluente do Arroio Grande e integrante da bacia hidrográfica do rio VacacaíMirim, da região hidrográfica do Guaíba (Chami, Deon \& Silva, 2014). O Arroio Manuel Alves revela uma dinâmica fluvial peculiar, definida por canais de grande energia de transporte nas vertentes de maior declive, o que potêncializa a ocorrência de inundações em períodos de intensa precipitação. A água, mostra-se, assim, relevante para a instituição da RPPN.

As características naturais e o legado de conservação motivaram a Fundação a solicitar junto da (SEMA) a instituição da área como uma RPPN. Como Organização Não Governamental, a Fundação assumiu um papel muito importante para a gestão da RPPN, através de ações de manejo junto à comunidade da região central do Rio Grande do Sul. Destacamos os convénio técnico-científico com a Universidade Federal de Santa Maria (UFSM) e a Universidade Federal do Pampa (UNIPAMPA), para a realização de projetos de extensão e pesquisa que auxiliam na gestão da área da RPPN.

O processo de instituição do Monte da Penha como Paisagem Protegida não partiu da Irmandade da Penha, mas da Câmara Municipal de Guimarães. A Irmandade de Nossa Senhora do Carmo da Penha, da Arquidiocese de Braga, conhecida como Irmandade da Penha, é atualmente proprietária de cerca de 60 hectares e um dos grandes impulsionadores da recuperação do monte. A partir da visita do rei D. Manuel II à Penha em 1909, foram desenvolvidas ações de promoção e conservação do Monte da Penha no âmbito da compra e restauração da vegetação (Pinto e Barroso, 2005). Há um conjunto de fatores que faz da Penha um local de culto de referência, sendo a Irmandade cogestora e promotora da conservação desta área. A palavra "penha" deriva da palavra latina pinna, que

\footnotetext{
${ }^{2}$ Áreas que possuem ecossistemas florestais biologicamente prioritários e viáveis para a conservação da biodiversidade, no caso a Mata Atlântica (RIO GRANDE DO SUL, 2014b)
} 
significa "rochedo", considerando que, até à segunda metade do século XX, esta paisagem era conhecida por grandes rochedos graníticos, sendo uma área desmatada (Pinto e Barroso, 2005).

O Município de Guimarães apresentou a candidatura de classificação e integração da Penha na Rede Nacional de Áreas Protegidas (Meireles et al., 2017) considerando atributos do património natural, como o geológico e o geomorfológico, com particular destaque para as rochas granitoides e formas que marcam a paisagem da Penha (Vieira et al., 2019). Outros valores são considerados, como o sítio arqueológico da Penha e o atributo hídrico.

O sítio arqueológico apresenta registos de ocupação desde o Paleolítico, pois as grutas existentes eram usadas como ponto de abrigo e a sua altitude facilitava as estratégias de segurança e defesa (Oliveira, 2001). Relativamente ao atributo hídrico, a relevância está nas minas de água da Serra da Penha que abastecem a cidade (Meireles et al., 2017) e o património hidráulico associado (Costa, 2014). Os atributos mencionados, foram assim apresentados para justificar a candidatura.

Segundo Viera et al. (2019) a Serra da Penha (Figura 2) apresenta um grande e diversificado número de atributos da geodiversidade, com caraterísticas geopatrimoniais. A estes valores está associado um conjunto de caraterísticas de âmbito cultural e ecológico, decorrente da relação secular estabelecida com o ser humano no âmbito religioso, na qual a Irmandade da Penha teve um papel fundamental. O Monte da Penha (Figura 2) é o ponto mais elevado da zona urbana de Guimarães, com altitude de 613 metros, permitindo visibilidade a partir de miradouros e percursos (Câmara de Guimarães, 2009). Localizado a sudeste da cidade, a área da proposta de Paisagem Protegida Local tem uma dimensão de cerca de 122 hectares (Carvalho,2014). Abrange toda a propriedade da Irmandade da Penha e propriedades no seu entorno, que desempenham o papel como uma zona tampão e se encontram limitadas por estradas, caminhos, limites de propriedades, definindo uma área alongada no sentido Norte-Sul (Vieira et al., 2019). 


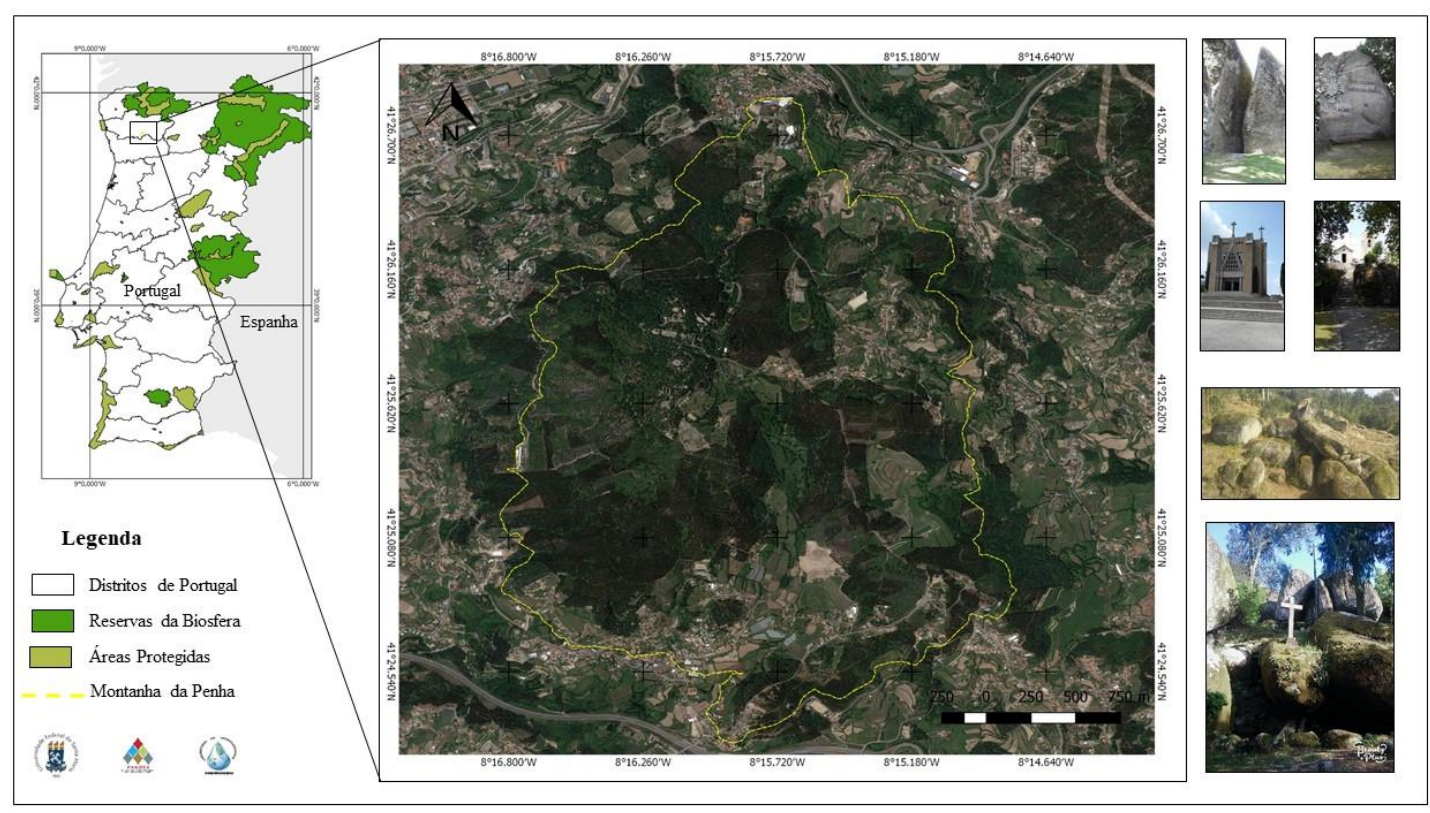

Figura 2- Localização do Monte da Penha

Segundo Fernandes (2014), esta área foi desprovida de vegetação arbórea (primeira metade do século $X X$, e preenchida por matos esparsos, onde eram visíveis as rochas graníticas que ainda se encontram à vista nos cabeços das vertentes. Contudo a Irmandade da Penha e a Comissão de Melhoramentos da Penha iniciaram um processo de reflorestamento, bem como, mais recentemente, têm vindo a realizar o manejo e limpeza no âmbito de prevenção de incêndios florestais.

A Serra possui uma diversidade de tipos de habitats relevantes em termos de biodiversidade, com uma flora "de uma enorme diversidade arbórea, onde predominam os carvalhos na sua maioria, mas também sobreiros, medronheiros, ciprestes, cedros e tílias" (Meireles, 2017, p. 43). O mesmo autor destaca, ainda, que a vegetação existente na Penha é densa, mas, no entanto, pouco variada. Isto devido as alterações históricas realizadas à flora natural.

Em tal contexto, verifica-se a importância do papel de atuação da Irmandade, entidade de cunho privado, na complementaridade da gestão da área da Penha com fins de proteção ambiental. Função semelhante é atribuída à Fundação MO'Ã, que atua diretamente em prol da conservação ambiental, através da RPPN. 


\subsection{O papel dos privados na gestão de áreas protegidas.}

Neste A criação de áreas protegidas é considerada uma relevante estratégia para a gestão do território pois estabelece limites e dinâmicas de uso e ocupação específicos. O controle e os critérios são definidos a partir da realidade em que encontramos buscando a valorização dos recursos naturais assim como conservar e/ou proteger a biodiversidade (Coad et al., 2015). Com uma grande influência de organizações não governamentais e reunindo órgãos públicos e estados de mais de 160 países a UICN, fundada em 1948, assumiu a missão de auxiliar a sociedade mundial a conservar a biodiversidade e a gerir de forma sustentável os recursos naturais. Com o objetivo de proteger a nível local, regional e mundial, a IUCN definiu áreas protegidas (UICN,2008), como "Uma área geográfica claramente definida, reconhecida, dedicado e gerenciado por todos meios efetivos, legais ou não, para garantir que conservação a longo prazo da natureza, bem como serviços ecossistêmicos e valores culturais associado a ele".

Em um contexto global a conservação da biodiversidade depende fortemente das áreas protegidas para deter sua perda e salvaguardar espécies para o futuro (Kamal, GrodzinkaJurczak \& Brown,2015). Para a World Comission on Protected Areas (WCPA) áreas como estas devem ser protegidas permanentemente, para benefício das gerações presentes e futuras (Dudley et al., 2008).

No âmbito deste trabalho sobre áreas protegidas privadas, seguimos o enquadramento da IUCN sobre parceiros privados: indivíduos e grupos de indivíduos, organizações nãogovernamentais (ONGs), corporações comerciais, empresas e, por vezes, corporações criadas por grupos de proprietários privados com fins lucrativos aos proprietários, centros de investigação, universidades, centros de investigações, ou entidades religiosas (lannuzzi, 2016). A discussão vem-se destacando, justamente pelos dados significativos das áreas privadas que abarcam, por exemplo: $73,8 \%$ do total das terras dos parques nacionais na Grã-Bretanha; 45\% das reservas biológicas da Costa Rica; 14 milhões de hectares de áreas privada na África Austral está envolvido em alguma forma de gestão da vida selvagem (NPA UK, 2011). 
As áreas protegidas privadas são instrumentos de política ambiental com potencialidades e desafios na sua gestão (Knight, Cowling, Difford \& Campbell, 2010) que requerem novos tipo de governança em contexto de dinâmicas sociais aceleradas (Weddel, 2002). Nas últimas décadas estas áreas aumentaram a partir do surgimento de políticas e estruturas legais que possibilitam parcerias na gestão. O Brasil está entre alguns dos primeiros países a definir novos instrumentos de gestão de áreas naturais, com as Reservas Particulares do Património Natural (RPPNs) (Figura 3) (Langholz, 2010).


Figura 3 - Atribuições da categoria de manejo RPPN.

Fonte: ICMBio, 2019

Essa categoria engloba 350 áreas protegidas em sete estados brasileiros, que correspondem a mais de 938 milhões de $\mathrm{m}^{2}$ protegidos (ICMBio, 2019). Entre as suas características está o carater de perpetuidade numa gestão que abarca parcerias e promove a conservação da natureza. Em Portugal, a Reserva da Faia Brava foi instituída em 2010 como a primeira área protegida privada nacional dentro de uma estrutura legal específica 
(Decreto-Lei n. 142/2008). O proprietário assume todos os compromissos que o processo de instituição envolve, bem como os objetivos estabelecidos pelas leis nacionais, como as atividades de conservação planejadas para a gestão da área, educação ambiental, pesquisa e visitação.

As áreas protegidas privadas contribuem nas políticas de conservação dos biomas e habitats em extinção. Frequentemente constituem-se como zonas-tampão e fragmentos relevantes para os corredores ecológicos dentro da rede de reservas naturais públicas (Langholz \& Lassoie, 2001).

No âmbito desse trabalho abordamos a categoria de Paisagem Protegida (Figura 4), considerando o caso do Monte da Penha.

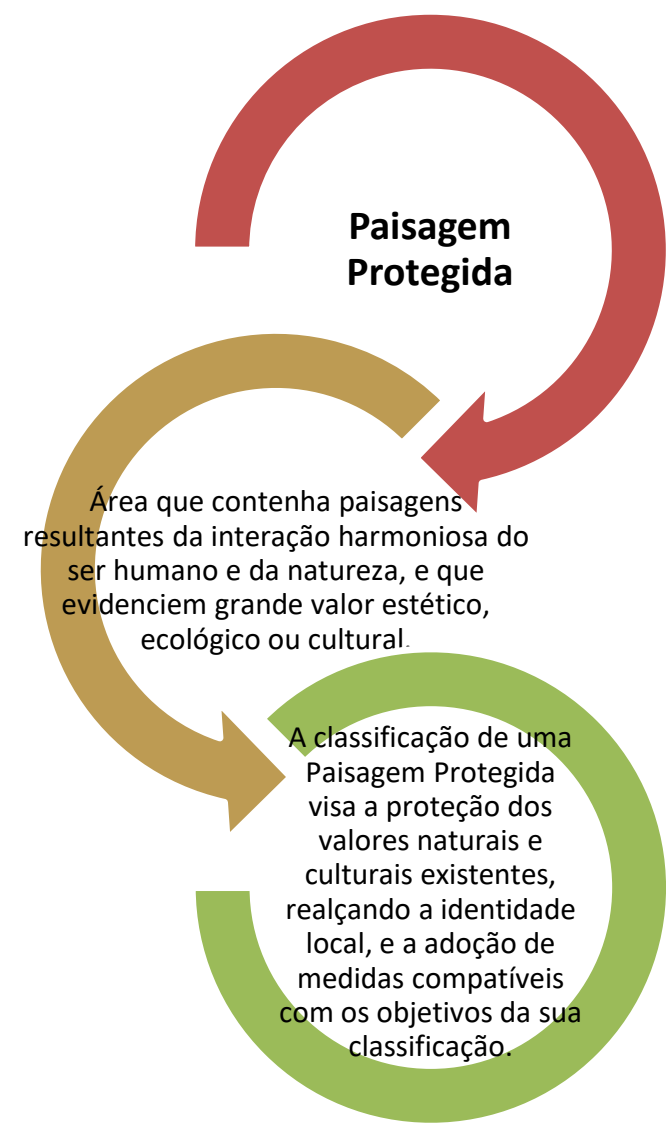

Figura 4 - Atribuições da categoria Paisagem Protegida

Fonte: Portugal, 1976. 
Segundo o decreto-lei no.613/76, de 27 de julho (Portugal, 1976), a Paisagem Protegida tem por objetivo proteger áreas rurais ou urbanas onde haja atributos da cultura e hábitos dos povos, expressos em construções e espaços organizados que mantenham as atividades, como a agricultura, o pastoreio e o artesanato. A promoção social, cultural e economia das populações residentes torna-se um pilar fundamental para que estas participem ativa e conscientemente, de forma sustentável. Com a publicação do decreto-lei no. 19/93, de 23 de janeiro (Portugal, 1993), a paisagem protegida passou a ter interesse regional ou local e a corresponder a uma área com paisagens naturais, seminaturais e humanizadas resultantes da interação harmoniosa entre o ser humano e a Natureza e que manifesta atributos de grande valor estético e/ou natural (Portugal, 2012).

\section{A gestão a partir do privado: 0 caso da Paisagem Protegida Local Monte da Penha e a RPPN Estadual MO’Ã}

Para este trabalho recorremos a um conjunto diversificado e numeroso de fontes documentais, quer primárias, quer secundárias. A investigação baseou-se sobretudo na consulta e análise de jornais nacionais e internacionais a partir de arquivos físicos e virtuais, artigos científicos nas bases periódicos (CAPES, EBSCO, SCIELO, Repositórios Científicos de Acesso Aberto de Portugal), documentos, trabalho de campo e entrevistas e partindo de palavras-chave predefinidas, revistas, relatórios e correspondência, bem como fotografias. Esta base de dados permitiu que desenvolvêssemos uma análise do papel do privado na gestão das áreas protegidas, trazendo o caso da RPPN MO'Ã com a gestão da Fundação MO'Ã e a Paisagem Protegida Local da Monte da Penha com parte da sua gestão pela Irmandade da Penha. Com foco na ocorrência de áreas protegidas no Brasil e Portugal, fezse necessário uma análise sobre o dominialidade (Quadro 1) na gestão das áreas protegidas. 
Quadro 1 - Dominialidade das Unidades de Conservação/Brasil e das áreas protegidas/Portugal.

\begin{tabular}{|c|c|c|c|}
\hline $\begin{array}{l}\text { Tipologia Unidades de } \\
\text { Conservação/Brasil }\end{array}$ & Domínio & $\begin{array}{c}\text { Tipologia Áreas } \\
\text { Protegidas/Portugal }\end{array}$ & Domínio \\
\hline Estação ecológica & Público & & \\
\hline Reserva biológica & Público & Parque Natural & Público \\
\hline Parque Nacional & Público & Parque Nacional & Público \\
\hline Monumento Natural & $\begin{array}{l}\text { Público, podendo, entretanto, } \\
\text { ser particular. }\end{array}$ & $\begin{array}{l}\text { Monumento } \\
\text { Natural }\end{array}$ & Público \\
\hline $\begin{array}{l}\text { Refúgio da vida } \\
\text { silvestre }\end{array}$ & $\begin{array}{l}\text { Público, podendo, } \\
\text { Entretanto, ser particular. }\end{array}$ & & \\
\hline $\begin{array}{l}\text { Área de Proteção } \\
\text { Ambiental }\end{array}$ & Público ou particular & & \\
\hline $\begin{array}{l}\text { Área de relevante } \\
\text { interesse ecológico }\end{array}$ & Público ou particular & Reserva Natural & Público \\
\hline Floresta nacional & Público & & \\
\hline Reserva extrativista & $\begin{array}{l}\text { Público, com uso concedido } \\
\text { às populações extrativistas. }\end{array}$ & & \\
\hline Reserva de fauna & Público & & \\
\hline $\begin{array}{l}\text { Reserva de } \\
\text { desenvolvimento } \\
\text { sustentável }\end{array}$ & Público & Paisagem Protegida & Público \\
\hline $\begin{array}{l}\text { Reserva Particular do } \\
\text { Patrimônio Natural }\end{array}$ & Particular & $\begin{array}{l}\text { Área } \quad \text { Protegida } \\
\text { Privada }\end{array}$ & Particular \\
\hline
\end{tabular}

Fonte: SNUC (2000), ICNF (2008) Org. autores.

Ao Vale observar que das categorias de áreas protegidas brasileiras, apenas a RPPN é de domínio privado. Contudo as demais permitem parcerias com entidades privadas consideradas fundamentais para a sua gestão e manutenção. No caso português, apenas a Área Protegida Privada é de domínio privado, porém as demais revelam a importância da cooperação partilhada com entidades privadas.

As categorias são diferentes pelo fato de serem baseadas em políticas ambientais específicas de cada país. No entanto a comparação é relevante visto tratarem-se de duas áreas de relevância para a proteção ambiental local e possuírem como base institucional o setor público com medidas de gestão de cunho privado. A Irmandade da Penha e a 
Fundação MO'Ã, mostram ações e medidas de gestão diferenciadas, porém não menos importante para a proteção da natureza (Figura 5):
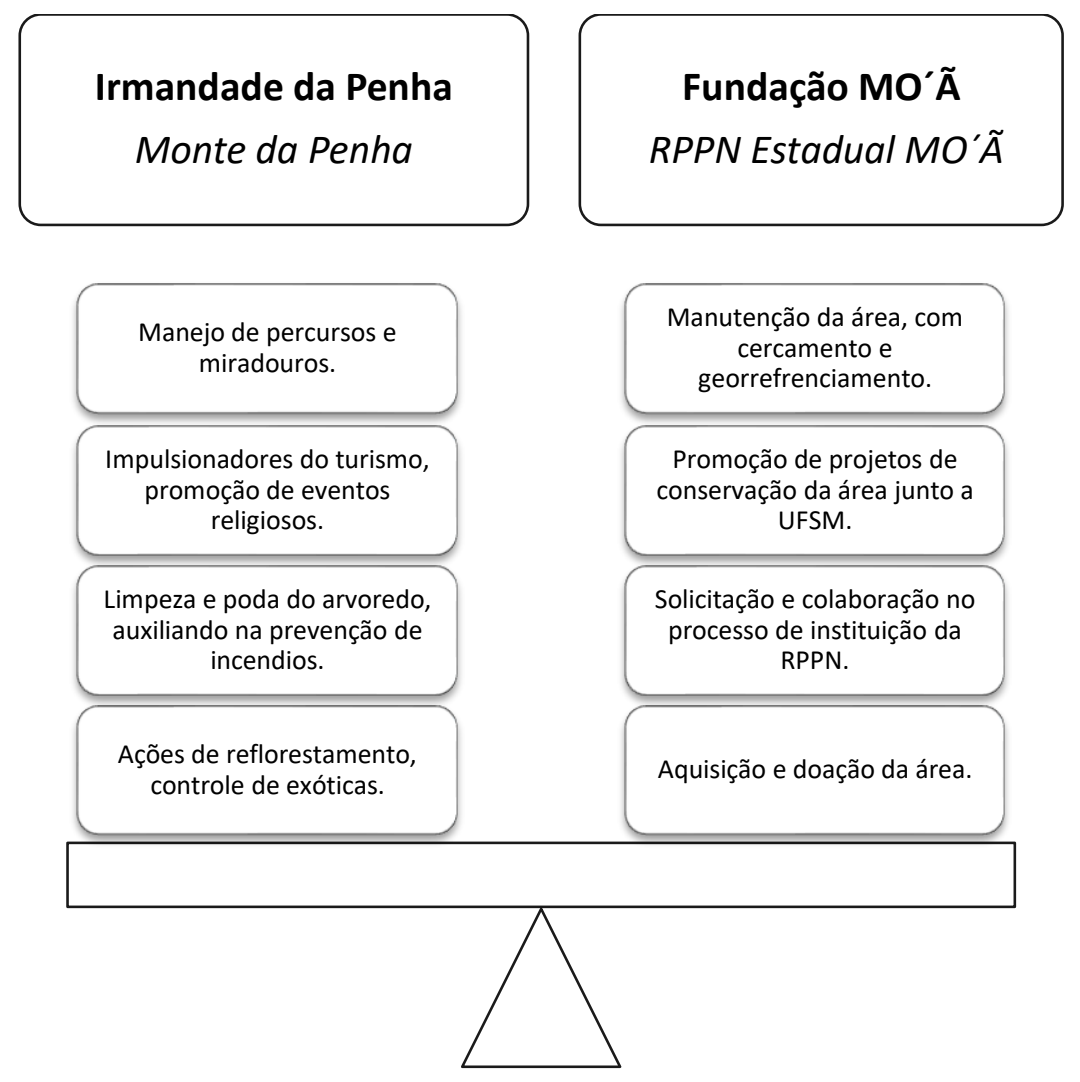

Figura 5 - Ações da Irmandade da Penha na Monte da Penha e a Fundação MO'Ã na RPPN Estadual MO'Ã.

A Irmandade da Penha intervém no Monte da Penha desde 1702, com os primeiros trabalhos na paisagem (Oliveira, 2001). Depois disso várias intervenções são realizadas no âmbito de melhoramentos nos acessos e estrutura para os cultos religiosos. Também várias ações de valorização ambiental foram lançadas pela Irmandade, como foi o caso da compra e plantio de arvoredo em 1909, iniciando um processo de reflorestamento da serra que se encontrava degradada (Oliveira, 2001). Este fato está diretamente ligado ao atual estado de conservação da área proposta para Paisagem Protegida local do Monte da Penha: a área propriedade da Irmandade é a que se encontra em melhor estado de preservação (Carvalho, 2014). Esta situação resulta do facto da Irmandade, proprietária do núcleo central da área (Figura 6) com cerca de 60 hectares, fazer a manutenção e conservação de uma área correspondente a 120 hectares correspondendo à zona tampão da Paisagem Protegida (Meireles et al., 2017). 




Terrenos da Câmara Municipal

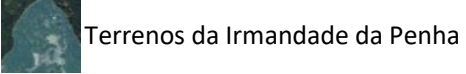

Área de intervenção 122 ha

Figura 6 - Áreas que compõe a Monte da Penha.

Fonte: Meireles et al., 2017.

O processo de instituição da Paisagem Protegida Local da Monte da Penha, iniciado em 2015, não partiu da Irmandade, mas sim da Câmara Municipal de Guimarães. Porém ambas as entidades reconhecem importância de estabelecer uma parceria de modo a garantir uma gestão coesa, uniforme e de partilha de responsabilidades (Meireles et al., 2017). O protocolo de cooperação estabelecido entre as duas partes permite estabelecer os domínios de interesse para ambas as partes, numa perspetiva de valorização recíproca, nomeadamente nos domínios da conservação da natureza, interação entre o sistema natural e paisagístico e o setor social, promoção de iniciativas no âmbito das artes, culto e cultura (Carvalho, 2014; Fernandes, 2014). A Irmandade da Penha tem implementado medidas de melhoramento que, por um lado, possam fornecer aos fiéis e visitantes um espaço com condições ao nível das infraestruturas, das acessibilidades, da segurança e da qualidade paisagística não descurando o respeito ao culto e à meditação e, por outro, 
prevenir incêndios florestais com trabalhos de limpeza (Novais, 2012). A Irmandade tem tido um papel crucial na gestão dos conflitos associados à prevenção de incêndios.

Outra infraestrutura fundamental é a existência do teleférico da Penha, único na região, facilitando o acesso e proporcionando uma maior visibilidade da área.

Atualmente a Irmandade mantem sua condição de cogestora da área. Um exemplo é a publicação do mapa da Monte da Penha, com informações alusivas ao Pio IX, à Gruta da Senhora de Lourdes, à Capela de Santa Catarina, ao Teleférico, ao Parque de Campismo e ainda uma proposta de atividades (Guimarães Turismo, 2012; Fernandes, 2014). A Irmandade da Penha, juntamente com a Turipenha ${ }^{3}$ e a Câmara Municipal trabalharam em parceria, no sentido de desenvolver um Mapa Turístico (Figura 7), cujo objetivo principal é de valorizar os recursos naturais desta área verde, potenciando assim a aproximação da Monte da Penha à população vimaranense e a quem visita Guimarães (Guimarães Turismo, 2020).

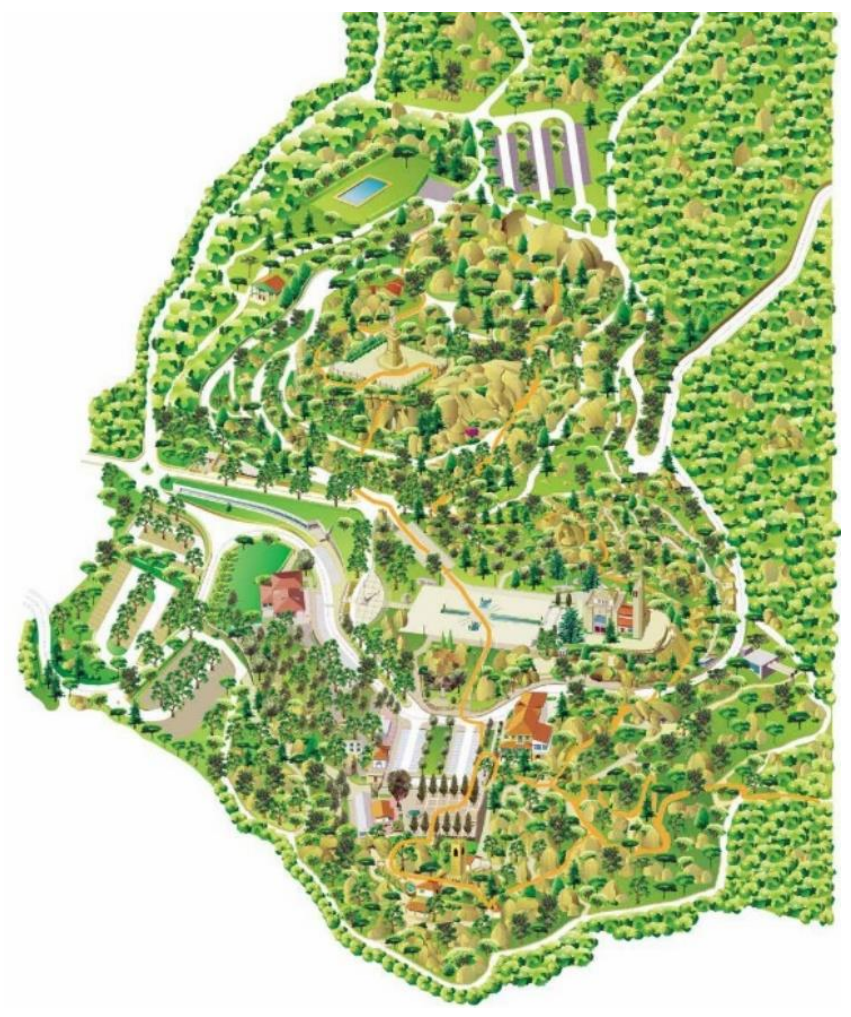

Figura 7 - Mapa turístico do Monte da Penha

Fonte: Camara de Guimarães, 2020.

\footnotetext{
${ }^{3}$ Cooperartiva de Turismo de Interesse Público, com atividade na área da animação turística, que gerencia o Teleférico de Guimarães e o Parque de Campismo da Penha, em Guimarães (Turipenha, 2015)
} 
Foram desenvolvidas diversas ações que envolveram a sensibilização dos visitantes na Penha como: Astronomia na Penha, Rampa da Penha, Trial Bike da Penha, Parque de campismo, Penha à vista, Vai-m’á Banda (Câmara Municipal de Guimarães, 2019).

No mesmo sentido a Fundação MO'Ã atua na área da RPPN, como cogestora junto ao poder publico. Desde a aquisição à sua instituição, a Fundação assumiu todos os compromissos que levaram à criação da RPPN, bem como a gestão de conflitos, como é exemplo mais premente a falta de acesso à área. O único acesso adequado, uma ponte de madeira construída pelo poder público, foi arrastada pela enxurrada em 2014 (Lamas, 2014). Atualmente a Fundação busca uma solução ecologicamente sustentável. Outra situação de conflito ocorreu em 2010 quando a Fundação impediu a passagem de uma linha de alta tensão sobre a área da RPPN que causaria a perda de uma faixa de $1 \mathrm{~km}$ de largura de vegetação. Foi solicitado junto a Secretaria Estadual do Meio Ambiente, a empresa de energia elétrica e a Prefeitura Municipal de Itaara o desvio da linha, o que foi acatado pelas entidades (Corrêa et al., 2019).

O papel de gestora da Fundação ultrapassa os limites da área para a Zona de amortecimento $^{4}$ da RPPN. A Fundação enquanto gestora da RPPN, promove outro pilar fundamental da sua missão, a Educação Ambiental, divulgando e sensibilizando para a conservação da biodiversidade através de várias atividades (Corrêa \& Figueiró, 2017). A Fundação se destaca por instituir a única RPPN da região central do estado, e desde a sua aquisição em 2007 pode-se observar a regeneração da vegetação (Figura 8), o que reforça sua atuação como gestora desta área (Corrêa et al., 2019).

\footnotetext{
${ }^{4}$ Resolução CONAMA no 428, de 17 de dezembro de 2010, atividades que possam afetar a zona de amortecimento só terão seu o licenciamento ambiental concedido após autorização do órgão gestor da unidade de conservação que ela circunda.
} 
A

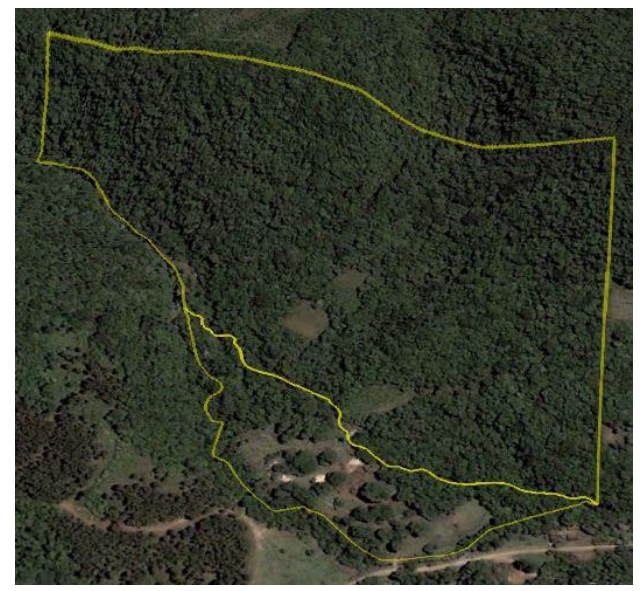

B

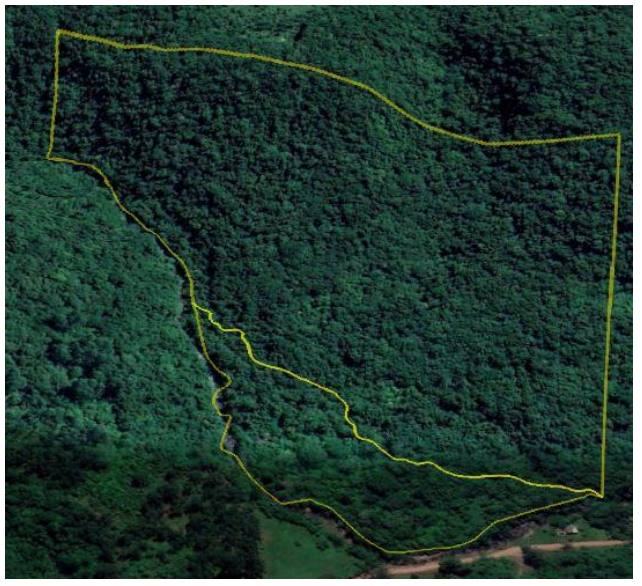

Figura 8 - A recuperação da vegetação da RPPN Estadual MO'Ã. A: imagem de satélite da RPPN em 2007. B: RPPN em 2020.

Fonte: Google Earth.

A execução do Projeto Saúde da água ${ }^{5}$ em 2014 e 2015 foi um marco relevante para esta entidade, pois o projeto articulou mais de 18 entidades privadas e publicas, com cinco eixos de atuação: Política de Resíduos sólidos; Monitoramento quali-quantitativo dos recursos hídricos; Levantamento da avifauna, mastofauna e ictiofauna; Restauração florestal; Educação Ambiental (Corrêa et al., 2018). A área de atuação deste projeto foi a sub-bacia do Arroio Manuel Alves, onde se localiza a RPPN Estadual MO'Ã, e todos os eixos permearam estudos na área. Com apoio e atuação da Fundação a partir do convénio técnico-científico com a UFSM, realizaram-se pesquisas como levantamento florístico, que permitiu descobrir a presença de duas espécies vegetais criticamente em perigo de extinção, a Araucaria angustifolia e Oxalis subvillos (Ferrarese, 2016). Cumprindo o papel de proteger a biodiversidade, foram realizados registros de uma espécie de rã ameaçada de extinção, a Aplastodiscus perviridis, que só de desenvolve em ambientes ecologicamente equilibrados e motivou a criação de uma mascote do Projeto Saúde da água, o Curi, que foi uma figura importante na sensibilização e participou das ações do projeto (Corrêa et al., 2018).

Tanto a Irmandade quanto a Fundação têm um papel relevante na gestão das suas áreas, com representatividade junto ao Poder Público e auxiliando da tomada de decisões

\footnotetext{
${ }^{5}$ O Projeto Saúde da Água foi um projeto da Fundação MO’Ã em parceria com a Universidade Federal de Santa Maria patrocinado pelo Programa socioambiental da Petrobrás.
} 
importantes para a conservação da biodiversidade. Mesmo estando em hemisférios diferentes e em categorias de áreas protegidas diferentes, a analise do papel dessas entidades mostra que o privado pode ser uma mais-valia na gestão de áreas protegidas

\section{Conclusões}

A proposta da Paisagem Protegida Local da Monte da Penha e a RPPN Estadual MO'Ã são gerenciadas por atores privados, a Irmandade da Penha e a Fundação MO'Ã, que desempenham um papel importante na política de conservação da natureza. A gestão partilhada pode ser um fator fulcral para enfrentar incertezas e agir sobre duas ameaças ambientais atuais: a perda de biodiversidade e as mudanças climáticas.

O desafio das discussões sobre o papel do privado em áreas protegidas resulta da necessidade de encontrar novos paradigmas sustentados pela governança, gestão participativa e resiliência.

A classificação do Monte da Penha como Paisagem Protegida Local é importante para a candidatura à Capital Verde europeia apresentada em 2017, sendo uma das estratégias da Comissão Europeia para enfrentar os desafios ambientais reconhecendo e recompensando os esforços locais para melhorar a qualidade ambiental das cidades. Cabe também nesta iniciativa a estratégia Municipal de combate as alterações climáticas

Entre os desafios que a Irmandade vai encontrar destacam-se a dinamização das parcerias e a gestão partilhada da Paisagem Protegida Local após a instituição da Monte da Penha.

Já a Fundação MO'Ã, tem como desafio firmar parcerias para a execução de novos projetos que favoreçam a visitação e ações de Educação Ambiental na RPPN.

Este trabalho reforça e estabelece debates necessários sobre áreas protegidas no âmbito Brasil-Portugal, com a intenção de fomentar a pesquisa à gestão sustentável dos territórios destes dois países.

\section{Referências}

Camara Municipal de Guimarães. Estratégia Municipal de Adaptação às Alterações Climáticas de Guimarães. 2016. Disponível em: https://www.cm-guimaraes.pt/municipio/camaramunicipal/servicos/ambiente/estrategia-municipal-de-adaptacao-as-alteracoes-climaticas. Acesso em $03 \mathrm{de}$ agosto de 2020 . 
Carvalho, S. A Qualificação da Paisagem da Encosta Noroeste do Monte da Penha (Guimarães). Tese de Mestrado. Universiade do Minho, Departamento de Geociências, Ambiente e Ordenamento do Território, 2014.

Chami,L;Deon,M;Silva,G.P. RPPN MO'Ã: Meios físico e biótipo. Estudo técnico. Disponível em: http://www.sema.rs.gov.br/upload/Estudo\%20T\%C3\%A9cnico.pdf. Acesso em 28 de julho de 2020.

Clough, P. 2000. “Encouraging Private Biodiversity: Incentives for Biodiversity Conservation on Private Land. Report to the Treasury." Wellington: New Zealand Institute of Economic Research. Disponível em: https://www.econstor.eu/bitstream/10419/205440/1/twp2000-25-1.pdf. Acesso em 24 de julho de 2020.

Coad, L. et al. Measuring impact of protected area management interventions: current and future use of the Global Database of Protected Area Management Effectiveness. Philosophical Transactions of the Royal Society B., v.370 (1681), p.1-5, 2015. Disponível em: https://royalsocietypublishing.org/doi/10.1098/rstb.2014.0281. Acesso em 03 agosto de 2020.

Corrêa, L.R; Figueiró, A.S. Proposta de uma trilha interpretativa na Reserva Particular do Patrimônio Natural Estadual Mo'ã, Itaara (RS). Revista Brasileira de Ecoturismo, São Paulo, v.10, n.3, ago/out 2017, pp.628-644. Disponível em: https://www.researchgate.net/publication/322097125_Proposta_de_uma_trilha_interpretativa_na_Reserva_ Particular_do_Patrimonio_Natural_Estadual_Mo'a_Itaara_RS_Proposal_for_an_Interpretative_Trail_in_The_P articular_Reservation_of_The_Natural_Heritage_Sta. Acesso em 03 de agosto de 20.

Corrêa, L.R; Figueiró, A.S; Foleto, E.M; Costa, F.S. A água como tema gerador para a educação ambiental: a experiencia do projeto Saúde da água. Anais do X Congresso Ibérico de Gestão e Planeamento da Água. Coimbra, 6-8 setembro 2018. Disponível em: https://fnca.eu/images/documentos/8-congresoiberico/Libro\%20actas\%208CIGPA.pdf. Acesso em 03 de agosto de 20.

Costa, F.S.. Mãe-d'água: Um contributo sobre o património hidráulico e o abastecimento público de Guimarães (noroeste de Portugal) In AGUA Y TERRITORIO. , 2014, v.3, 77-88.

Fernandes, P. A estrutura verde da Penha e envolvente. Dissertação de mestrado. Universidade do Minho, 2014.

Ferrarese, M.D. Floristica de uma Reserva Particular do Patrimônio Natural em fragmento de Mata Atlântica(Itaara,RS,Brasil). Dissertação (de mestrado agrobiologia) 2016, 80p.

GUIMARÃES TURISMO. Guimarães:Percussos de Pedestres. Capital europeia da cultura, 2012.

GUIMARÃES TURISMO. Mapa da taxa da Penha. 2020. Disponível em: https://www.guimaraesturismo.com/pages/222?news_id=24. Acesso em 03 de agosto de 20.

lannuzzi,G. Privately protected areas as a policy tool for nature conservation: the case of Portugal. Portugal, território de territórios. Atas do IX Congresso Português de Sociologia. 2016. Disponível em: https://www.researchgate.net/publication/313842650_Private_Protected_Areas_as_policy_instruments_to_t ackle_environmental_challenges_discussing_potentialities_and_pitfalls. Acesso em 24 de julho de 2020.

IUCN - International Union for Conservation of Nature. 2008. Disponível em: https://www.iucn.org/. Acesso em 28 de julho de 2020.

Knight, A.T., R.M. Cowling, M. Difford, and B.M. Campbell. "Mapping Human and Social Dimensions of Conservation Opportunity for the Scheduling of Conservation Action on Private Land." Conservation Biology 24: 1348-1358. 2010. Disponível em: https://pubmed.ncbi.nlm.nih.gov/20345404/. Acesso em 03 de agosto de 20 .

Lamas, J.P. Itaara libera acesso à localidade de Rincão dos Minellos. Disponível em: https://gauchazh.clicrbs.com.br/geral/noticia/2014/12/itaara-libera-acesso-a-localidade-de-rincao-dosminellos-cj5vtkh190u9exbj0igx631bm.html. Acesso em 16 de junho de 2020.

Langholz, J. Global Trends in Private Protected Areas and their implications for the Northern Great Plains. Great Plains Research 20, (1): 9-16, (2010). Disponível em: https://digitalcommons.unl.edu/greatplainsresearch/1076/. Acesso em 03 de agosto de 20. 
Langholz, J., Lassoie, J. P., Lee, D., Chapman, D. Economic considerations of privately owned parks, Ecological Economics, 33, (2), 173-183, (2000). Disponível em: https://www.sciencedirect.com/science/article/abs/pii/S092180099900141X. Acesso em 03 de agosto de 20.

Meireles, F. (2017). Candidatura da Paisagem Protegida Local da Montanha da Penha.

Meireles, F; Fernandes, J; Salgado, R; Silva, P. Rota da biodiversidade: Montanha da Penha. 2017. Disponível em: https://www.cm-guimaraes.pt/cmguimaraes/uploads/writer_file/document/8150/eco_revista_13.pdf. Acesso em 03 de agosto de 2020.

NOVAIS, J.P.O. Santuário da Penha: Um percurso pela história de fé do povo de Guimarães. Tese de mestrado, Universidade Católica Portuguesa Faculdade de Teologia, 2012.

NPA UK (National Parks Authority, UK). 2011. "National Parks of the UK. Disponível em: http://www. nationalparks.gov.uk. Acesso em 03 de agosto de 20.

Oliveira, M. Modificações do Uso do Solo - A Serra da Penha. Tese de Mestrado. Universidade do Minho, Instituto de Ciências Sociais, Secção de Geografia. Guimarães. Setembro 2001.

Pinto, E; Barroso, P. Penha: Retrospectiva Iconográfica da Sacralização da Montanha, Orgal impressores, Guimarães, 2005.

Portugal (1976). Presidência do Conselho de Ministros. Decreto-lei no.613/76, de 27 de Julho. Definição, constituição e gestão de reservas. Documento no. 1029 - Legislação -acional, publicado em 27-07-1976. Disponível em: http://siddamb.apambiente.pt. Aceso em 03 de agosto de 20.

Portugal (1993). Presidência do Conselho de Ministros. Decreto-lei no. 19/93, de 23 de Janeiro. Rede Nacional de Áreas Protegidas. Documento no 479 - Legislação -acional, publicado em 23- 01-1993. Disponível em: http://siddamb.apambiente.pt. Acedido a 03 de agosto de 2020.

Portugal. Decreto Lei 135 de 29 de junho de 2012. Aprova a orgânica do Instituto da Conservação da Natureza e Florestas, I. P. (Instituto de Conservação da Natureza e das Florestas, I. P.). Diário da República, 1. série n.으 125 , 29 jun. 2012. Disponível em: http://data.dre.pt/eli/dec-lei/135/2012/06/29/p/dre/pt/html; Acesso em 25 de abril de 2019.

RIO GRANDE DO SUL. Portaria n. 143, de 23 de dezembro de 2014b. Reconhece o Corredor Ecológico da Quarta Colônia, como instrumento de gestão territorial para promoção da conectividade entre o Parque Estadual da Quarta Colônia e demais alvos prioritários de conservação da biodiversidade identificados na região. Secretaria do Meio Ambiente. Diário Oficial do Estado, Porto Alegre, RS. 16 dez. 2014. Disponível em: <http://www.biodiversidade.rs.gov.br/arquivos/14601366082014_Portaria_SEMA_n_143_Corredor_Ecologic o_4_Colonia._nota_COM_MAPA.pdf>. Acesso em: 05 jan. 2016.

RIO GRANDE DO SUL. Portaria n. 80, de 15 de junho de 2015. Cria a Reserva Particular do Patrimônio Natural Estadual MO'Ã e dá outras providências. Secretaria do Ambiente e Desenvolvimento Sustentável. Diário Oficial do Estado. Porto Alegre, RS. 15 jun. $2015 . \quad$ Disponível em: <http://www.sema.rs.gov.br/conteudo.asp?cod_menu=218\&cod_conteudo=9207>. Acesso em: 28 de julho de 2020.

Kamal, S; Grodzińska-Jurczak, M; Brown, G. Conservation on private land: a review of global strategies with a proposed classification system, Journal of Environmental Planning and Management, 58:4, 576-597, (2015). Disponível

em: https://www.tandfonline.com/doi/full/10.1080/09640568.2013.875463\#aHR0cHM6Ly93d3cudGFuZGZvb mxpbmUuY29tL2RvaS9wZGYvMTAuMTA4MC8wOTYOMDU2OC4yMDEzLjg3NTQ2Mz9uZWVkQWNjZXNzPXRyd WVAQEAw. Acesso em 03 de agosto de 2020.

UNEP-WCMC and IUCN (2016). Protected Planet Report 2016. UNEP-WCMC and IUCN: Cambridge UK and Gland, Switzerland. Disponível em: https://www.protectedplanet.net/c/protected-planet-report-2016. Acesso em 30 de julho de 2020. 